\title{
PRACTICAL MODEL OF CEMENT BASED GROUT MIX DESIGN, FOR USE INTO LOW LEVEL RADIATION WASTE MANAGEMENT
}

\author{
LIDIA RADU - Lecturer, PhD, Technical University of Civil Engineering, Faculty of Railways, Roads and \\ Bridges, e-mail: lradu31@yahoo.com \\ NASTASIA SACA - Lecturer, PhD, Technical University of Civil Engineering, Faculty of Railways, Roads and \\ Bridges, e-mail: nastasiasaca@gmail.com \\ CLAUDIU MAZILU - Lecturer, PhD, Technical University of Civil Engineering, Faculty of Railways, Roads and \\ Bridges, e-mail: claudiumazilu@yahoo.com \\ MARIA GHEORGHE - Professor, PhD, Technical University of Civil Engineering, Faculty of Railways, Roads \\ and Bridges, e-mail: maria_gh2001@yahoo.com \\ IONELA PETRE - PhD, Eng., CEPROCIM S.A, e-mail: ionela.petre@ceprocim.ro

\begin{abstract}
The cement based grouts, as functional performance composite materials, are widely used for both immobilisation and encapsulation as well as for stabilization in the field of inorganic waste management. Also, to ensure that low level radioactive waste (LLW) are contained for storage and ultimate disposal, they are encapsulated or immobilized in monolithic waste forms, with cement -based grouts.

The paper includes some research data referring to cement based grout mix design for use as encapsulating/immobilizing system for low level radioactive waste. The work includes cementbased-grout mix design method used practically into establishing of the optimum grout mix based on the water/cement ratio, cement/sand ratio in order to achieve application requiered values of fluidity, segregation resistance, shrinkage and mechanical strengths. These engineering grout characteristics present relevance for simulation experiments of radionuclide leaching from LLW cement grout encapsulation system.
\end{abstract}

Keywords: grout mix design, flowability, shrinkage, compressive strengths, low level waste encapsulation

\section{Introduction}

The cement-based grouts are very fluid fine mortars carried out of cement, fillers and fine sand, namely fine granular material with conventional sand function, and high water reducers and superplasticizers admixtures. The grouts are commonly used in engineering works, as soil reinforcement and civil engineering $[1,2]$, also in nuclear area preplaced-super heavy aggregate concrete applications [3] and in waste management area.

The encapsulating/immobilizing into impermeable grouts is an appropriated and inexpensive method used for encapsulation of low level radioactive waste (LLW) [4 - 6] and also, for the inertization of heavy metal- non radioactive waste. The efficiency of the method results from the compositional and functional modeling ability to achieve the required performance level. The grout main component is the cement and the inert and pozzolanic or cementitious additions. The type and weight or volume ratios of the cement and additions have a decisive influence on the long term durability of the LLW encapsulation systems.

Radionuclides can be said to be immobile if the characteristics of fluidity, dispersibility and freedom of movement within a waste package are eliminated. Immobilisation is therefore any process by which mobile waste fractions are conditioned in such a way that the potential for migration or dispersion of the radioactivity associated with a waste, at any stage during its longterm management, is reduced to an acceptable degree, in accordance with Guidance on the Immobilisation of Radionuclides in Wasteforms [7]. 
Technological and functional performance of advanced composites for encapsulation/ immobilization of low level radioactive waste and with cumulated ability of ionizing radiation absorption/shielding is developed as a necessity to protect health and the environment in the context of increasing impact nuclear technology in various applications and volume of radioactive waste $[8,9]$. The main technical characteristics of the fresh grout are flowability or capacity to fill the narrowest spaces between comminuted solid LLW and the segregation resistance.

Some principal hardened grouts properties are the appropriated mechanical strengths (from derived fluid impermeability) and dimensional stability. The grout functional characteristics are described by the cement-grout matrix compatibility with the LLW, due to solidification/stabilization (immobilization) capacity, of radionuclides from LLW. The main secondary resources used for the grouts were the primary lead slag and pulverized fly ash with characteristics described into our previous works [10]. The grout mix establishing is closely linked to the fundamental role of cement, compatible by the chemistry and hydrosilicates gel structure with chemical precipitation and/or physical sorption of radionuclides.

In this context the paper presents a cement-based-grout mix design method used practically into establishing of the optimum grout mix for simulation experiments of radionuclide leaching from LLW - cement grout encapsulation system. The grout mix design criteria, presented in this paper, are based on the principle of the components properties transfer toward encapsulation/immobilization performances of cement based monolithic waste forms.

\section{Experimentals}

\subsection{Materials}

The matrix of grouts contains cement with slag lead content by $30 \%$ (noted as $\mathrm{SPb} 3$ ), experimentaly obtained. The physical characteristics of cement are presented in Table 1.

Table 1

The characteristics of cement with lead slag content

\begin{tabular}{|l|l|l|}
\hline \multicolumn{2}{|l|}{ Characteristics } & $\mathrm{SPb} 3$ \\
\hline \multicolumn{2}{|l|}{ Density, $\mathrm{g} / \mathrm{cm}^{3}$} & 3.35 \\
\hline \multicolumn{2}{|l|}{ Blaine specific surface, $\mathrm{cm}^{2} / \mathrm{g}$} & 4090 \\
\hline \multicolumn{2}{|l|}{ Water for standard consistency, \% } & 24.9 \\
\hline \multirow{2}{*}{ Setting time } & initial & $>8 \mathrm{~h}$ \\
\cline { 2 - 3 } & final & $<24 \mathrm{~h}$ \\
\hline Stability, mm & 4.0 \\
\hline Bending strength, $\mathrm{MPa}$ & 2 zile & 1.9 \\
\cline { 2 - 3 } & 7 zile & 5.9 \\
\cline { 2 - 3 } & 28 zile & 7.1 \\
\hline Compressive strength, MPa & 2 zile & 16.3 \\
\cline { 2 - 3 } & 7 zile & 32.3 \\
\cline { 2 - 3 } & 28 zile & 41.9 \\
\hline Cement strength class & $32.5 \mathrm{R}$ \\
\hline
\end{tabular}

Lead primary slag $(\mathrm{SPb})$ were taken from former ROMPLUMB S.A. dump. There are not identified in our country work of primary lead slag valorization in cement matrix composites, but exist attempts referring to inorganic polymers [11]. The $\mathrm{SPb}$ used in this research was characterized by various content of lead $(6.6 \%$ as $\mathrm{PbO})$ and copper $(4.6 \% \mathrm{CuO})$. The lead primary slag was used as addition at cement obtain for use in grout, in proportion of $30 \%$. The physical characteristics of lead slag were: density-3850 kg/m 3 , bulk density- $1880 \mathrm{~kg} / \mathrm{m}^{3}$ and water absorption- $0.4 \%$. The sand used was river sand with particle size $<2 \mathrm{~mm}$.

The superplasicizers (SP) based on the policarboxylated ethers were used as admixture for grouts. 


\subsection{Grout mixes}

The grout mixes were characterized by different cement $(\mathrm{SPb} 3)$ : sand volume ratios $(\mathrm{c} / \mathrm{s})$ namely 1:1.25, 1:1.9 and 1:2.5 compared with reference cement paste.

All of the mixes had various water-cement ratios (w/c) of $0.3,0.5$ and 0.7 respectively, using the same sand particle size distribution, according to figure 1. In this paper are showed the mix grout design based on sand 2 .

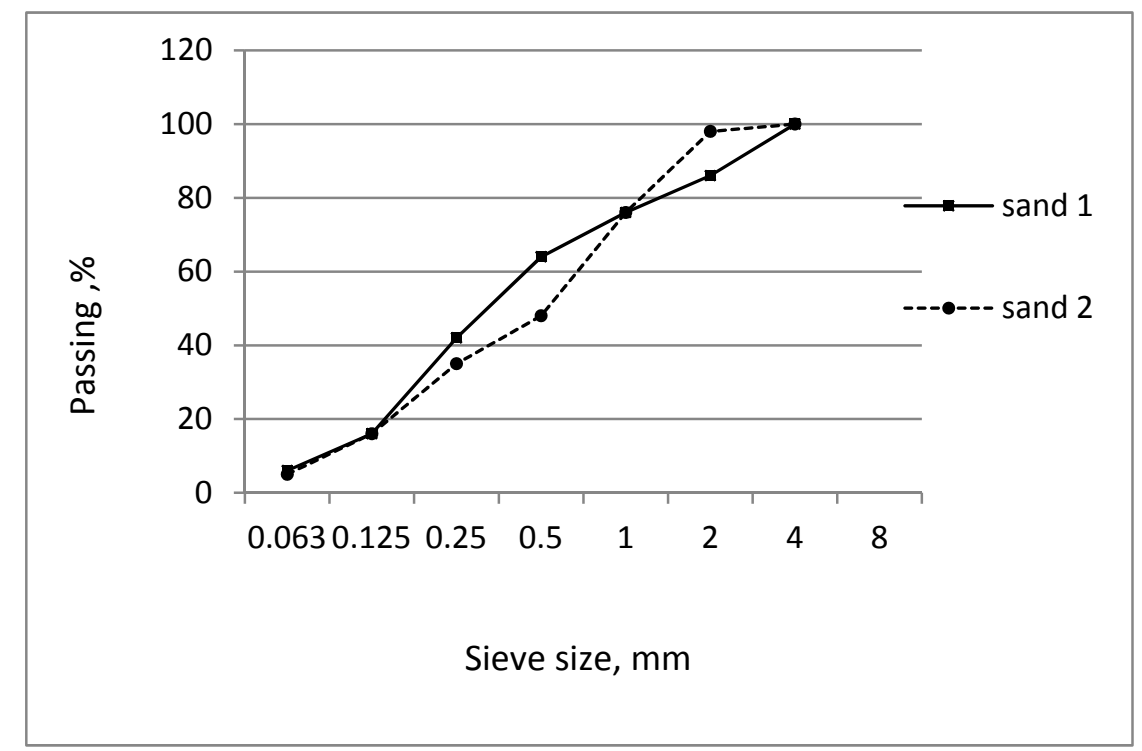

Fig. 1 - Sand particle size distribution

The grout mixes are presented in the table 2 .

Table 2

The grout mixes

\begin{tabular}{|c|c|c|c|c|}
\hline Mix no. & $\begin{array}{c}\text { Cement SPb-3: Sand } \\
\text { mass ratios }\end{array}$ & $\begin{array}{c}\text { Cement SPb-3: Sand } \\
\text { volume ratios }\end{array}$ & w/c ratio & SP (\%) \\
\hline 1 & $1: 1$ & $1: 1.25$ & 0.3 & 1.6 \\
\hline 2 & $1: 1$ & $1: 1.25$ & 0.5 & 1.6 \\
\hline 3 & $1: 1$ & $1: 1.25$ & 0.7 & 1.6 \\
\hline 4 & $1: 1.5$ & $1: 1.9$ & 0.3 & 1.6 \\
\hline 5 & $1: 1.5$ & $1: 1.9$ & 0.5 & 1.6 \\
\hline 6 & $1: 1.5$ & $1: 1.9$ & 0.7 & 1.6 \\
\hline 7 & $1: 2$ & $1: 2.5$ & 0.3 & 1.6 \\
\hline 8 & $1: 2$ & $1: 2.5$ & 0.5 & 1.6 \\
\hline 9 & $1: 2$ & $1: 2.5$ & 0.7 & 1.6 \\
\hline
\end{tabular}

\subsection{Methods}

The materials density was determined by the pycnometric and hydrostatic methods and bulk density by using a known volume vessel.

The water absorption was tested by immersion method (for 24 hours).

The method used to measure grout flowability was based on the the flow cone (Marsh funnel) test according to ASTM-C939 [12].

Grout mixes in hardened state were monitored for shrinkage and mechanical strengths time evolution. The prisms of $4 \times 4 \times 16 \mathrm{~cm}$ used for mechanical strengths and shrinkage testing. The high lead slag content of grout, led to diminishing of cement hydration rate and, consequently, 
to final setting time increasing. Therefore, the demoulding time of samples was greater than $24 \mathrm{~h}$. The grout compressive strength and the shrinkage are considered acceptance criterions for secure LLW encapsulation [13].

\subsection{Grout mix design principle used into experimental work. Theory background}

Grout mix design is a selection of raw materials, in optimum proportions, to give cement based composite namely grout, with required properties in fresh and hardened states for particular application, respectively encapsulation/immobilization of solid LLW. There are many mix design methods for self-compacting cement based composite promoted by the development of self-compacting concrete technology. The grout mix design outlined in this article is based on the theoretical data [14-19] and on the author's applied procedure in previous researches at determination of the grout composition as precursor of self-compacting concrete mix design.

\subsubsection{Close aggregate packing method}

This type of mix design method determines mix proportions by obtaining the least voids volume between coarse particle of sand based, firstly, on packing model, then applying paste needed volume to fill the void.

The method based on the Densified Mixture Design Algorithm (DMDA). DMDA was derived from the maximum density need and excess paste theory $[15,16]$. The design concept consist to achieve minimum water and cement content by applying filler (e.g. limestone, fly ash) to fill the void between coarse sand particle of $1 / 2 \mathrm{~mm}$ granular fraction and cement paste to attain the least void (figure 2).

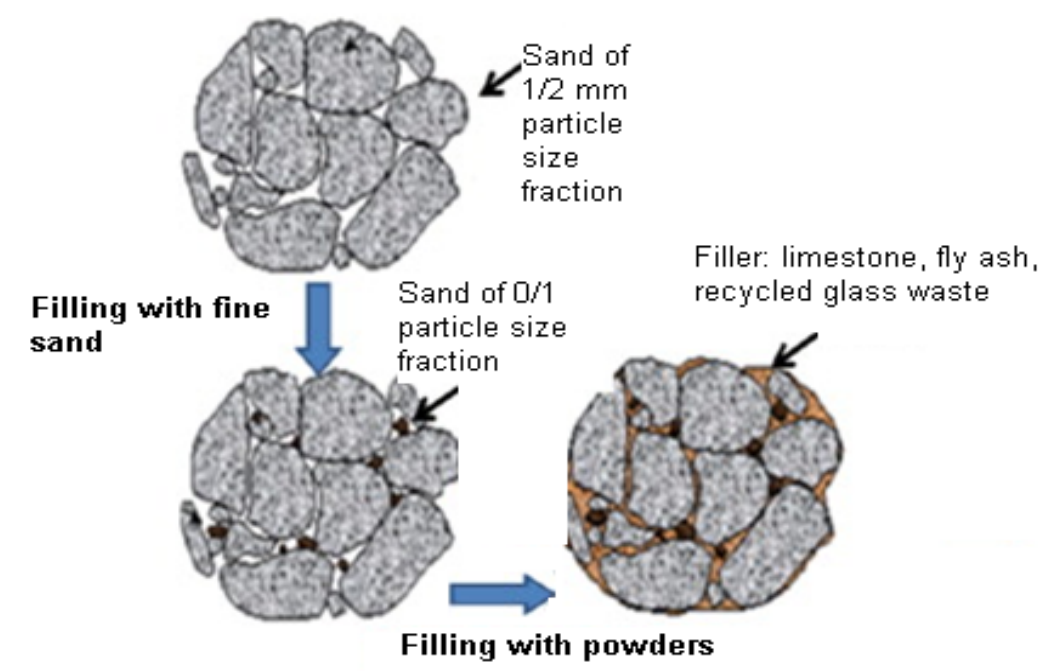

Fig. 2 - The principle of solid packing procedure [modified after 16]

This method is notable for its importance but is not that easy to apply. However, there are no adequate methods to justify uniformity of the mixture. The close solid particles packing method mainly considers the relationships between paste and sand. Hence, this method is simpler and requires a smaller amount of binders.

\subsubsection{The packing factor method}

The packing factor (measured by filling factor, FF) to control the content of cement and filler proportion in grout mix [16, 17] was used, in modified form in this work. The principal consideration of the method was to fill with the reasonable volume of binder paste the voids of sand 
(also called aggregate) framework. The packing factor of aggregate is defined as the mass ratio of tightly packed aggregate to that of loosely packed aggregate, in the grout case, the sand particle.

Calculation of the volume ratio sand/paste, Vs/Vpaste for grout, take into consideration volume fraction or paste filling ratio of voids between sand particles, noted fv. Thus:

$$
\mathrm{f}_{\mathrm{v}}=\mathrm{V}_{\mathrm{s}} / \mathrm{V}_{\text {paste }}
$$

A filling ratio in the $(0.87 \ldots 0.95)$ are a corresponds to an excess paste with $5 \ldots 15 \%$ higher than the volume of sand, Vs, and is given by the ratio Vs/ Vpaste values from 100/105 to $100 / 115$.

It follows that the estimated volume of sand is:

$$
\mathrm{V}_{\mathrm{s}}=\mathrm{f}_{\mathrm{v}} \times \mathrm{V}_{\text {paste }}=(0,87 \ldots 0,95) \mathrm{V}_{\text {paste }}
$$

In the choosing of the filling factor must take into account of the geometrical and surface features of the aggregate, namely Dmax, type of aggregate (gravel aggregate require a smaller volume of paste respectively higher fv values than the crushing aggregate).

The fraction of sand $\left(\Psi_{\mathrm{s}}\right)$ is calculated in the relationship between the selected grout filling ratio fv, and mortar volume fraction, with the equations:

$$
\begin{aligned}
& \Psi_{\mathrm{s}}=\mathrm{V}_{\mathrm{s}} /\left(\mathrm{V}_{\text {paste }}+\mathrm{V}_{\mathrm{s}}\right) \\
& \Psi_{\mathrm{s}}=\mathrm{f}_{\mathrm{v}} / 1+\mathrm{f}_{\mathrm{V}} \\
& \mathrm{V}_{\mathrm{s}} /\left(\mathrm{V}_{\text {paste }}+\mathrm{V}_{\mathrm{s}}\right)=\mathrm{f}_{\mathrm{v}} / 1+\mathrm{f}_{\mathrm{v}}(5)
\end{aligned}
$$

It was thus established on the basis of calculation, the amount of sand under $2 \mathrm{~mm}$, as river sand or recycled sand, which must be close in value to the amount of paste.

This method is simple and uses a smaller amount of binders. The packing factor determines the aggregate content and influences the strength, flowability and self-compacting ability. However, how to determine the optimum sand to aggregate ratio or the packing factor is not explained. These two values are assumed empirically to carry out the mixture design.

\subsubsection{Empirical method}

A recent method of cement based-grout mix design proposed by Satyarnoa et al. is based on the well-known absolute volumes of each material principle, but with some minor modifications, based on their mass or volume ratios [20]. So if, for example, the volume ratio cement:sand:water is $1: a: b$, according to this method should be met following relationship:

$$
\frac{V_{c} \cdot \rho_{a g c}}{d_{c} \cdot \rho_{w}}+\frac{a \cdot V_{c} \cdot \rho_{a g s}}{d_{s} \cdot \rho_{w}}+\frac{b \cdot V_{c} \cdot \rho_{w}}{\rho_{w}}=1
$$

where:

$\mathrm{V}_{\mathrm{c}}$ is the necessary volume of cement per cubic meter grout;

$\rho_{\text {agc }}$ - bulk density of cement;

$\rho_{\text {ags }}$ - bulk density of sand;

$\rho_{\mathrm{w}}$ - density of water;

a - volumetric portion of sand;

$\mathrm{b}$ - volumetric portion of water;

$\mathrm{d}_{\mathrm{c}}$ - relative density of cement;

$\mathrm{d}_{\mathrm{s}}$ - relative density of sand.

For known w/c ratio, the relationship (6) becomes:

$$
\frac{V_{c} \cdot \rho_{a g c}}{d_{c} \cdot \rho_{w}}+\frac{a \cdot V_{c} \cdot \rho_{a g s}}{d_{s} \cdot \rho_{w}}+\frac{w / c \cdot V_{c} \cdot \rho_{c}}{\rho_{w}}=1
$$


From Eqs. 6 or 7 can be easily determine the necessary volume of cement per $\mathrm{m}^{3}$ of grout $\left(\mathrm{V}_{\mathrm{c}}\right)$ because it is the only unknown in the equations. With $\mathrm{V}_{\mathrm{c}}$ can then find $\mathrm{V}_{\mathrm{s}}$, respectively $\mathrm{V}_{\mathrm{w}}$. For this example, it follows that: $\mathrm{V}_{\mathrm{s}}=\mathrm{aV}_{\mathrm{c}}$ and $\mathrm{V}_{\mathrm{w}}=\mathrm{bV}$.

\subsubsection{Experimental method}

On the basis of the same principle of absolute volumes, in this paper we have used a method in accordance with previous works [21-23]. In previous research referring to selfcompacting concrete mix design we used in equation real absolute volume values (not relative) of each component.

Using the experimentally test results of the flow time, 28 days-compressive strenghts and the dimensional stability, their correlation with water/cement ratio and the sand/cement volume ratio can be drawn. Then using empirical equations of their correlations can be fouund the optimal values of ratios w/c and s/c, implicitly the necessary volume of cement per $\mathrm{m} 3$ of grout $(\mathrm{Vc})$ and of the sand (Vs).

\section{Results and discussions}

The optimal ratio of w/c was assessed in relation to grout fluidity, segregation resistance and mechanical strengths.

The optimum w/c ratio at which the grout need to have high fluidity, as required in the application, was assessed graphically from the variation of flow time versus the $\mathrm{w} / \mathrm{c}$ ratios, in figure 3 .

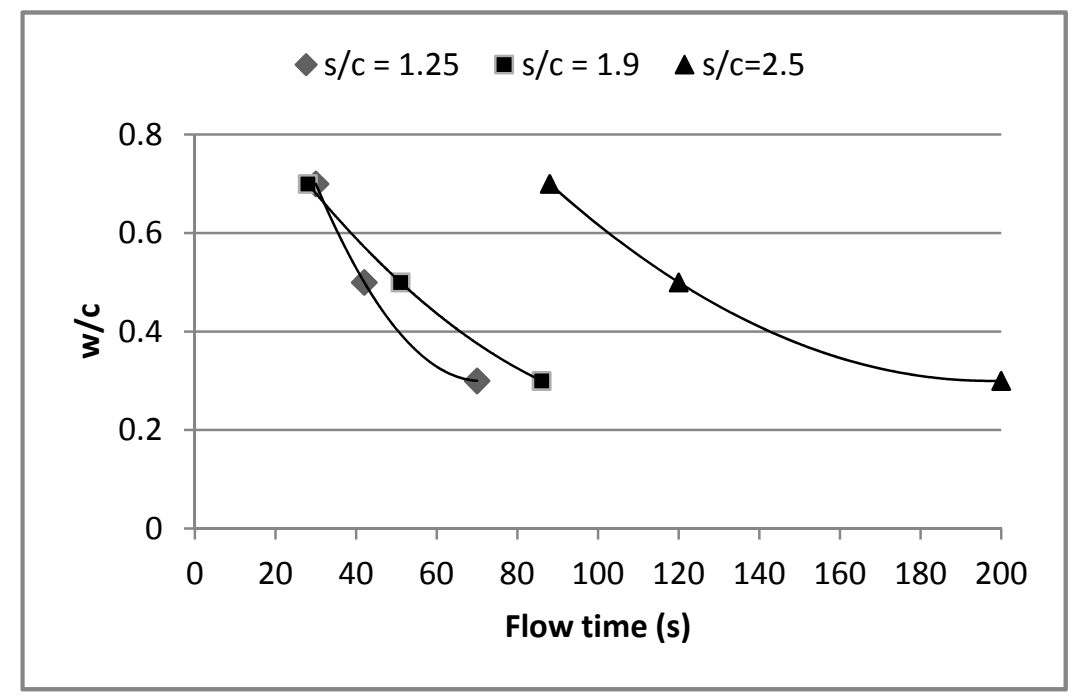

Fig. 3 - The grout flow time variation versus w/c ratio at several s/c values

It has been found the optimum w/c ratio at which flow time was minim and without segregation and bleeding. The flow time values decrease with diminishing of the sand/cement $(\mathrm{s} / \mathrm{c})$ ratio. The time flow lower values are given of mixtures with ratios s/c reduced, namely s/c of 1.25 and 1.9 , in the area of 30-90 s, comparatively with flow time more than $90 \mathrm{~s}$, for the mix with s/c of 2.5. For example, the flow time value of $40 \mathrm{~s}$ is achieved at $\mathrm{w} / \mathrm{c}$ ratio of 0.5 for grout mix with $\mathrm{s} / \mathrm{c}$ of 1.25 . The flow time values below $40 \mathrm{~s}$ are obtained at values of $\mathrm{w} / \mathrm{c}$ higher than 0.5 . Increasing the water / cement ratio leads to reducing of flow time, but is unfavorable resistance to segregation, and above all of compression strength.

The correlation of cement/sand volume ratio, expressed as the volume of sand to cement volume, $\mathrm{s} / \mathrm{c}$, and minimum water-cement ratio, $(\mathrm{w} / \mathrm{c}) \mathrm{min}$ that can still be used to satisfy the flow cone test, is plotted in figure 4 . 


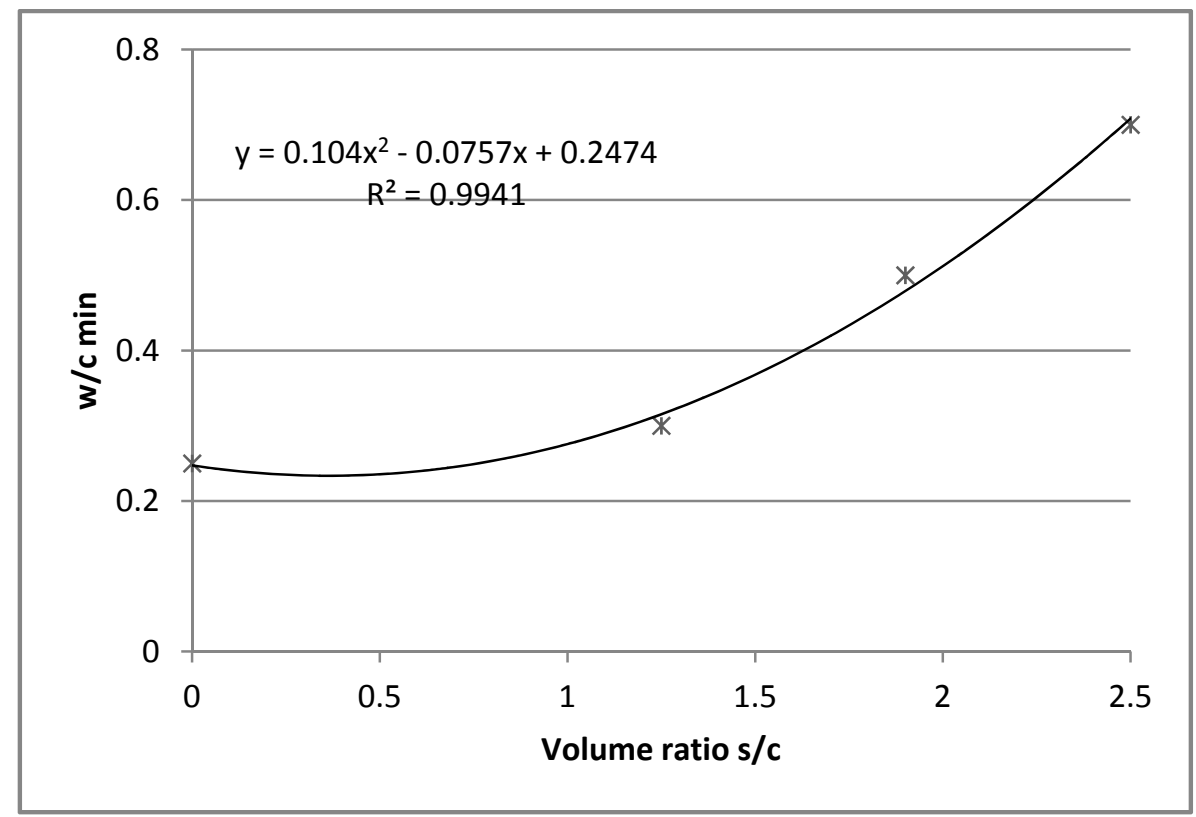

Fig. 4 - Correlation between s/c and (w/c)min

The following trends can be found:

- Values of $(\mathrm{w} / \mathrm{c})_{\min }$ as variable depending of s/c ratio, may be deducted from the regression equation with a high correlation coefficient of 0.9941.

$$
(\mathrm{w} / \mathrm{c})_{\min }=0.104(\mathrm{~s} / \mathrm{c})^{2}-0.0757(\mathrm{~s} / \mathrm{c})+0.2474
$$

- The minimum water-cement ratio $(\mathrm{w} / \mathrm{c})_{\min }$ that satisfies the target values of the grout flow time is semnificantly influenced by the s/c ratio.

- The s/c volume ratios in the area values of $0.5-1.5$ can be considered the values corresponding to an effective dosage of cement, $\mathrm{V}_{\mathrm{c}}$.

The correlation between $\mathrm{s} / \mathrm{c}$ and grout mechanical strengths (compressive strength $\mathrm{f}_{\mathrm{c}}$, respectively bending strength $f_{i}$ ) at 28 days age are shown in figures 5 and 6 .

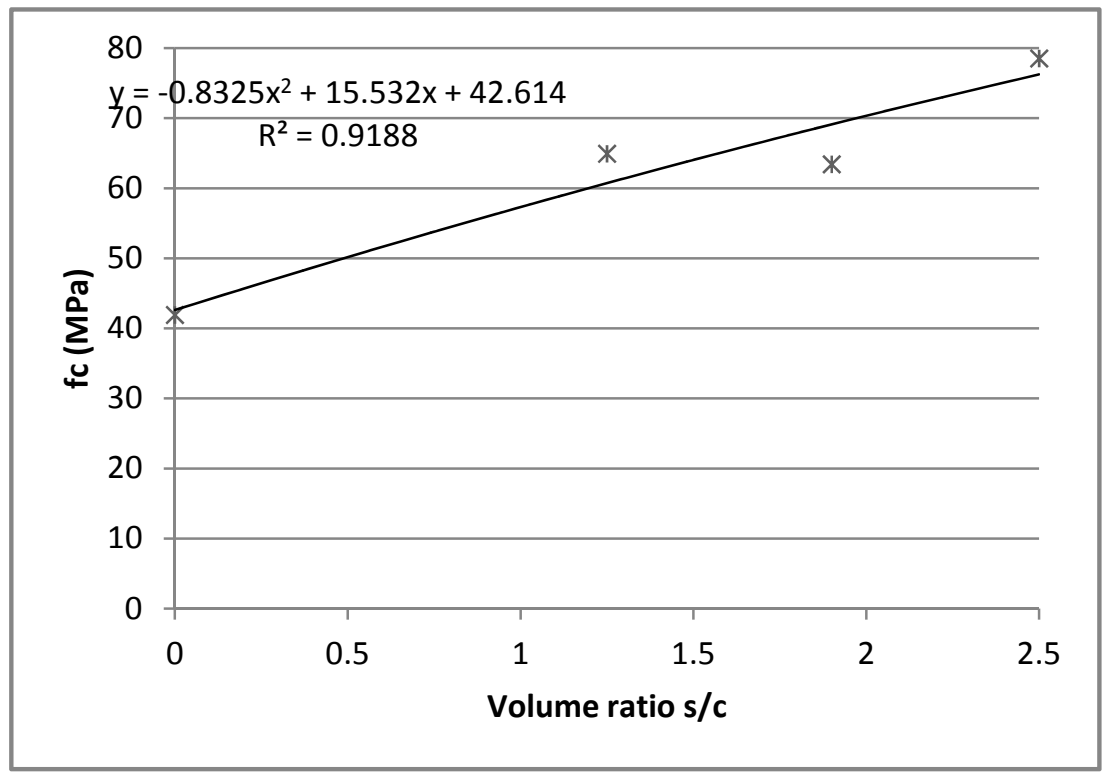

Fig. 5 - Correlation between $\mathrm{s} / \mathrm{c}$ and $\mathrm{f}_{\mathrm{c}}$ at 28 days 


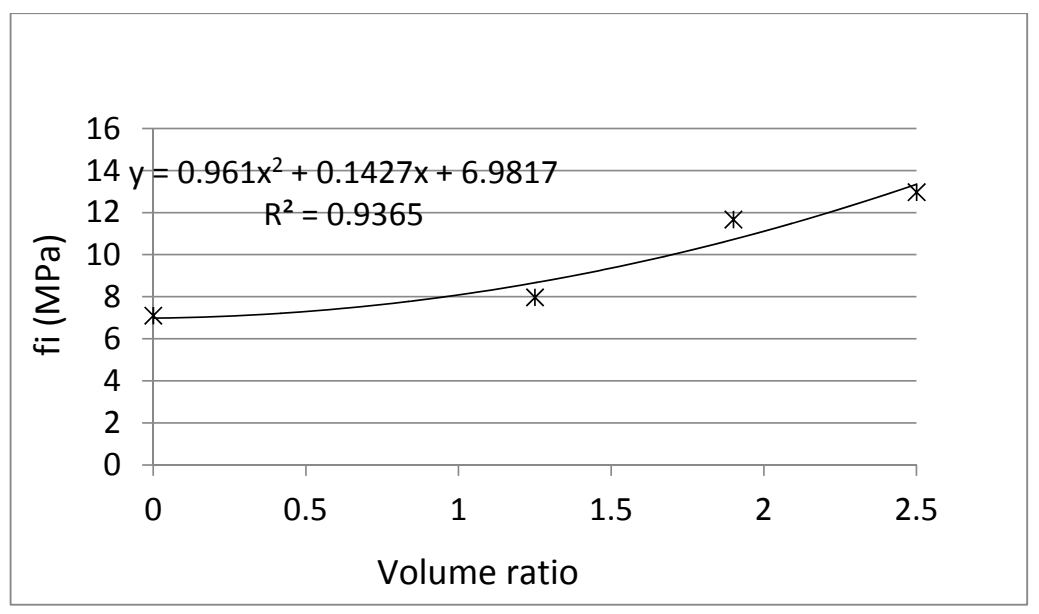

Fig. 6 - Correlation between $\mathrm{s} / \mathrm{c}$ and $\mathrm{f}_{\mathrm{i}}$ at 28 days

There are the following tendencies:

- The grout mechanical strengths depends semnificantly on s/c, at the same water/cement ratio, of 0.3 , with the good correlation coefficients values.

- Mechanical strength increase according increasing the amount of sand namely ratio s/c.

- The bending strength is better correlated with the s/c value, because this sttrengths type is more sensible to potential cracking of cement paste (namely cement dosage) exces.

- The regression curves shown in figures 5 and 6, Eqs. 9 and 10 can be used to predict the grout $\mathrm{s} / \mathrm{c}$ volume, at w/c 0.3 , for achieve the target 28 days- compressive and bending strengths values.

$$
\begin{aligned}
& \mathrm{f}_{\mathrm{c}}=-0.8325(\mathrm{~s} / \mathrm{c})^{2}+15.532(\mathrm{~s} / \mathrm{c})+42.614 \\
& \mathrm{f}_{\mathrm{i}}=0.961(\mathrm{~s} / \mathrm{c})^{2}+0.1427(\mathrm{~s} / \mathrm{c})+6.9817
\end{aligned}
$$

The correlation between $\mathrm{s} / \mathrm{c}$ and the shrinkage of grouts are presented graphically in figure 7 .

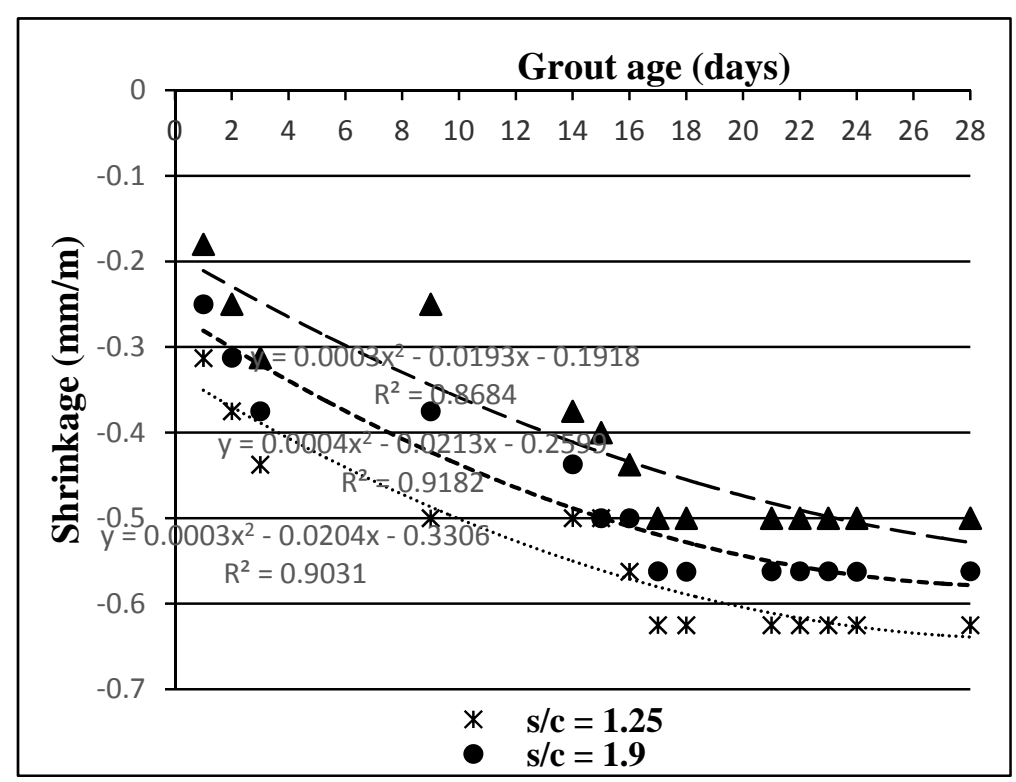

Fig. 7 - Correlation between $\mathrm{s} / \mathrm{c}$ and the shrinkage of grouts

The large volume of powder, in relation to the volume of coarse sand, is the main cause of the shrinkage increase. At a constant water / cement ratio, we can determine optimal sand / cement ratio for a minimal shrinkage and a high resistance to segregation of the grout. The grouts with the highest volume of sand ( $\mathrm{s} / \mathrm{c}$ ratio of 2.5 ) had the lowest values of shrinkage. The shrinkage 
grew gradually by reducing the cotent (volume) of sand and a rise of the cement concretised by $\mathrm{s} / \mathrm{c}$ ratio values of 1.9 and respectivelly 1.25 .

In conclusion, referring to $\mathrm{s} / \mathrm{c}$ influente on shrinkage $(\varepsilon)$ time $(\mathrm{t})$-evolution as $\varepsilon=\mathrm{f}(\mathrm{t})$ there are the following comments:

- The shrinkage of grouts depends, significantly, on s/c at the same water/cement ratio of (the applied value of 0.3 ).

- The shrinkage increases with the s/c decreasing, respectively, with cement volume. The grouts with sand /cement ratio of 2.5 show the lowest values of shrinkage.

- Therefore, the 28-days-shrinkage values were of $0.50 \mathrm{~mm} / \mathrm{m}, 0.562 \mathrm{~mm} / \mathrm{m}$ and $0.625 \mathrm{~mm} / \mathrm{m}$ for the s/c values of 2.5, 1.9 and, respectively, 1.25. Consequently, an optimal value of the $\mathrm{s} / \mathrm{c}$ of 1.9 can be considered.

- The lower values of the correlation coefficients can be explained by some errors dues of the measuring system.

- The regression equations shown in figure 7, can be used to predict the grout shrinkage, at the given s/c ratio as following:

$$
\begin{aligned}
& \varepsilon_{1.25}=0.0003(\mathrm{t})^{2}-0.0204(\mathrm{t})-0.3306 \\
& \varepsilon_{1.9}=0.0004(\mathrm{t})^{2}-0.0213(\mathrm{t})-0.2599 \\
& \varepsilon_{2.5}=0.0003(\mathrm{t})^{2}-0.0193(\mathrm{t})-0.1918
\end{aligned}
$$

The correlation between $\mathrm{s} / \mathrm{c}$ and the need of water per grout cubic meter $\mathrm{Vw}$ is shown in figure 8 . The need of water was correlated with minimum water-cement ratio, (w/c)min that can still be used to satisfy the flow cone test requiered values.

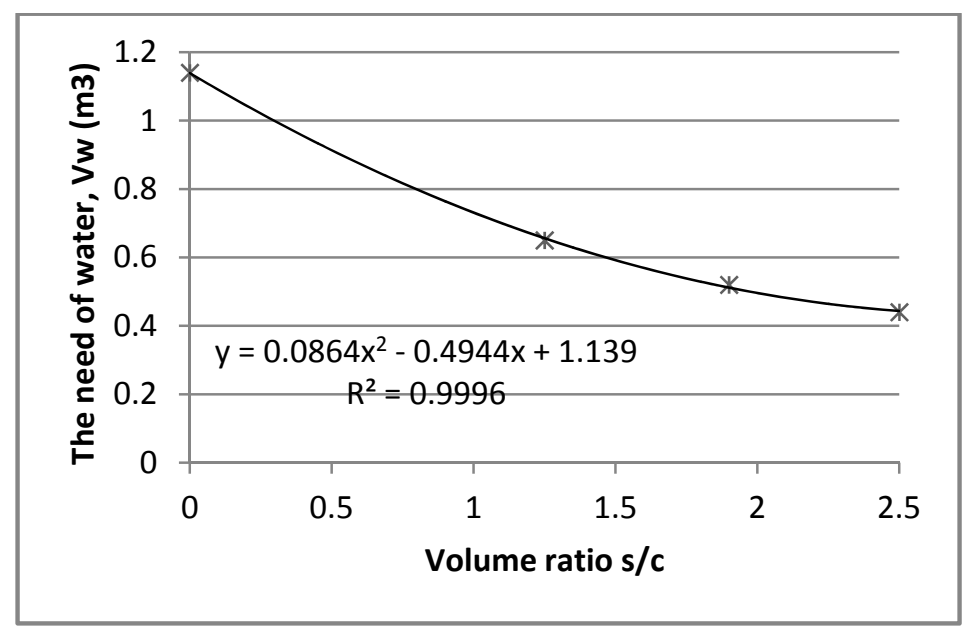

Fig. 8 - Correlation between s/c and the need of water per cubic meter of grout

The main comment arising are:

- The need of water in the grout mix decreases with increase of the $\mathrm{s} / \mathrm{c}$ volume ratio.

- The corelation coefficient of 0.9996 predict a very good possibility to estimate the optimum water volume at a given $\mathrm{s} / \mathrm{c}$ volume ratio.

- Therefore, for the s/c volume ratio of 1.9 may be used a water volume of 0.52 cubic meters.

- From regression analysis shown in figure 8, Eq. 14 can be found and used to calculate the need of $\mathrm{V}_{\mathrm{w}}$ water volume per cubic meter of grout mix.

$$
\mathrm{V}_{\mathrm{w}}=0.0864(\mathrm{~s} / \mathrm{c})^{2}-0.4944(\mathrm{~s} / \mathrm{c})+1.139
$$


Using the empirical equations found from regression analyses discussed above, the following practical procedure to carry out grout mix design are suggested the following steps:

1. The selection of the appropriate $\mathrm{s} / \mathrm{c}$ value to be used for the grout mix by considering the purpose of the grout application and the requirement of compressive strength at 28 days using Eq. 9.

2. Based on the selected $\mathrm{s} / \mathrm{c}$, follows to determine the minimum water-cement ratio $(\mathrm{w} / \mathrm{c}) \mathrm{min}$ to be applied using Eq. 8, and the need of water volume per cubic meter Vw using Eq. 14.

3. It is calculated the need of cement weight Wc in $\mathrm{kg}$ using Eq. 15.

$$
\mathrm{W}_{\mathrm{c}}=\rho_{\mathrm{w}} \cdot \mathrm{V}_{\mathrm{w}} /(\mathrm{w} / \mathrm{c})
$$

4. It is calculated the cement volume Vc in $\mathrm{m} 3$ using Eq. 16.

$$
\mathrm{V}_{\mathrm{c}}=\mathrm{W}_{\mathrm{c}} / \rho_{\mathrm{agc}}
$$

5. Finally, it is calculated the sand volume Vs in $\mathrm{m} 3$ using Eq. 17.

$$
\mathrm{V}_{\mathrm{s}}=\mathrm{V}_{\mathrm{c}}(\mathrm{s} / \mathrm{c})
$$

\section{Conclusions}

The work includes cement-based-grout mix design method used practically into establishing of the optimum grout mix based on the water/cement ratio, cement/sand ratio in order to achieve application requiered values of fluidity, segregation resistance, shrinkage and mechanical strengths. These engineering grout characteristics present relevance for simulation experiments of radionuclide leaching from LLW - cement grout encapsulation system.

The procedure proposed for grout mix design is based on laboratory experimental data used in some empirical equations based on regression analyses.

In accordance with the obtained regression equations can be established the trend of the fresh and hardened characteristics, in correlation with mix ratios, namely, w/c and s/c.

The minimum water-cement ratio $(\mathrm{w} / \mathrm{c})_{\min }$ that satisfies the target values of the grout flow time is semnificantly influenced by the $\mathrm{s} / \mathrm{c}$ ratio.

Based on the ratio $(\mathrm{w} / \mathrm{c})_{\min }$ corresponding to $\mathrm{s} / \mathrm{c}$ volume ratios in the area values of $0.5-1.5$ can be determined an effective dosage of cement, $\mathrm{V}_{\mathrm{c}}$.

The grout mechanical strengths increase with grouth of $\mathrm{s} / \mathrm{c}$ ratio, at the same water/cement ratio, of 0.3 , with the good correlation coefficients values.

Based on the regression equations were selected the appropriated mix compositional parameters to ensure the development of target characteristics of grouts - high values of fluidity, segregation resistance, and compressive strengths.

In the paper is presented a practical procedure to carry out grout mix design in five steps which led to assessing of cement and sand volumes.

The model of grout mix design was only developed in accordance with specific laboratory data of the Research Center for the Recovery of Mineral Waste in Construction Materials of Technical University of Civil Engineering.

Grout mix design is a critical step to obtain high quality product. A good grout mix design method should consider: applicability into target areas; strong robustness (flowability and segregation stability for variable raw materials); technical requirements, sustainability and cost. So far, there is no method fully meet these all requirements. Consequently, appropriate model of grout mix design should be selected according to specified requirements, the low level waste encapsulation, in the present research. 


\section{ACKNOWLEDGEMENTS}

This work was performed by Partnerships Programme in priority areas -PN II, developed with the support of MEN - UEFISCDI, contract no. 234/2014.

\section{References}

[1]. Guyer, J.P. (2009). Introduction to Soil Grouting, Continuing Education and Development, Inc., 9 Greyride Farm Court Stony Point, NY 10980.

[2]. ACI Committee. (1997). Guide for the Use of Preplaced Aggregate Concrete for Structural and Mass Concrete Applications, ACI Committee 304.1 R-92.

[3]. UFGS-03372. (2006). Preplaced-Aggregate Concrete, Division 03-Concrete, Section 03 37 00, Unified Facilities Guide Specification.

[4]. Sugaya, A., Tanaka, K., Akutsu, S. (2011). Cement Based Encapsulation Experiments for Low-Radioactive Liquid Waste at Tokai Reprocessing Plant, 11078 WM2011 Conferences, 27 February - 3 March 2011. Phoenix, AZ

[5]. Mauke, R., Wollrath, J., Müller-Hoeppe, N., Becker, D. A. \& Noseck, U. (2012). Overview of recent and future work on material development and usage of cementitious materials in salt repositories. Radioactive Waste Management NEA/RWM/R (2012) no. 3/REV

[6]. Akkurt, K., Günoglu, C., Basisgit \& Akka, A. (2013). Cement Paste as a Radiation Shielding Material. Acta Physica Polonica A 123(2), 341-342

[7]. Waste Package Specification and Guidance Documentation WPS/903. (2007). Guidance on the Immobilisation of Radionuclides in Wasteforms. Number: 532508

[8]. Department of Energy and Climate Change (DECC) and the Nuclear Decommissioning Authority (NDA). (2012). Radioactive Wastes in the UK: A Summary of the 2010 Inventory. http://www.world-nuclear.org/info.

[9]. International atomic energy agency. (2003). Radioactive Waste Management Glossary. Vienna

[10].Gheorghe, M., Saca, N. \& Radu, L. (2014). Valorization of mineral waste with heavy metals content into silicate matrix. $14^{\text {th }}$ International Multidisciplinary Scientific Geoconference, SGEM 2014, GeoConference on Nano, Bio and Green-Technologies for a sustainable future, 423-430. Doi: 10.5593/sgem2014B62.

[11].Onisei,' S., Pontikes, Y., Van Gerven, T., Angelopoulos, G.N., Velea, T., Predica, V. \& Moldovan, P. (2012). Synthesis of inorganic polymers using fly ash and primary lead slag. Journal of Hazardous Materials 205-206, 101-110.

[12].Standard Test Method for Flow of Grout for Preplaced-Aggregate Concrete (Flow Cone Method), American Standard of Testing Materials.

[13].Ishikura, T., Ueki, H., Ohnishi, K. \& Oguri, D. (2004). Utilization of Crushed Radioactive Concrete for Mortar to Fill Waste Container Void Space. Journal of nuclear science and technology 41(7), 741-750.

[14].Domone P. Proportioning of self-compacting concrete (2009).- the UCL method.

[15].Hwang, C. \& Tsai, C. (2005). The effect of aggregate packing types on engineering properties of selfconsolidating concrete. SCC'2005-China: 1st international symposium on design, performance and use of selfconsolidating concrete. RILEM Publications SARL, In: Zhiwu Yu et al., editors.

[16].Wang, X., Wang, K., Taylor, P. \& Morcous G. (2014). Assessing particle packing based self consolidating concrete mix design method. Constr Build Mater 70, 439-452.

[17].Caijun, S., Zemei, W., KuiXi, L. \& Linmei, W. (2015). A review on mixture design methods for selfcompacting concrete. Construction and Building Materials 84, 387-398Sun, Z., Young, C. (2014). Bleeding of SCC pastes with fly ash and GGBFS replacement. J Sustain Cem Based Mater.

[18].Hu, J., Wang, Z., \& Kim Y. (2013) Feasibility study of using fine recycled concrete aggregate in producing self-consolidation concrete. J Sustain Cem Based Mater 2(1), 20-34.

[19].Satyarnoa, I., Solehudina, A. P., Meyartoa, C., Hadiyatmokoa, D., Muhammada, P. \& Afnan, R. (2014). Practical method for mix design of cement-based grout, Procedia Engineering 95, 356 - 365.

[20].Gheorghe, M., Saca, N., Ghecef, C., Pintoi, R. \& Radu, L. (2011). Self compacted concrete with fly ash addition. Romanian Journal of Materials 41(3), 201-210.

[21].Gheorghe, M., Saca, N. \& Radu, L. (2008). The filler influence on the selfcompacted concrete properties.

[22].Romanian Journal of Materials 38 (3), 212-223.

[23].Gheorghe, M. (2009). Technical Specifications on self-compacting concrete production. Preliminary draft. Contract MDRT ICECON 435/2009, www.psc.ro/. 